\title{
Influence of Human Saliva on the Development of Artificial Erosions
}

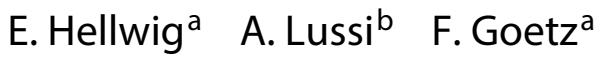 \\ ${ }^{a}$ Department of Operative Dentistry and Periodontology, Dental School and Hospital, Albert-Ludwigs University \\ Freiburg, Freiburg, Germany; ${ }^{b}$ Department of Preventive, Restorative and Pediatric Dentistry, University of Bern, \\ Bern, Switzerland
}

\section{Key Words}

Enamel $\cdot$ Erosion $\cdot$ Human saliva $\cdot$ Microhardness

\begin{abstract}
It was hypothesized that saliva from patients with erosion exhibits lower protective efficacy compared to saliva from patients without erosion, based on in vitro enamel softening studies. A total of 645 enamel specimens were distributed among seven experimental groups. Saliva was gathered from each of 10 volunteers without clinical signs of dental erosion and from 10 patients exhibiting severe erosive defects. Aliquots of $50 \mathrm{ml}$ of saliva from each patient were mixed with sour drops or citric acid, respectively. Pooled saliva, sour drops and citric acid mixed with water served as controls. The enamel specimens were soaked in the respective mixture for $5 \mathrm{~min}$ and were subsequently incubated in pure saliva for $2 \mathrm{~min}$. This cycle was repeated three times, then the specimens were kept in $100 \mathrm{ml}$ of saliva for $8 \mathrm{~h}$. Surface microhardness was evaluated at the beginning of the experiment and after each cycle. During the experiments, microhardness decreased significantly in all groups except for the pure saliva group. For sour drops and citric acid mixed with saliva from patients without erosion, the final microhardness was higher compared to the mixture of the two erosive compounds with saliva from patients with erosion. The storage of saliva for $8 \mathrm{~h}$ resulted in a certain amount of rehardening, with the highest level of rehardening being ob-
\end{abstract}

served in the group that was least demineralized (sour drops plus saliva from patients without erosion). It is concluded that salivary components play a crucial role in the development of dental erosion.

Copyright @ 2013 S. Karger AG, Basel

Many etiological aspects of erosion have been evaluated in sophisticated in vitro models. However, these models can mimic only single aspects of the complex physiological ecology of the mouth, and even in situ studies do not reflect reality. Factors such as different ways of taking up acidic food compounds, salivary composition, and abrasion of eroded tooth hard tissues by the tongue and cheeks exert a certain influence on the development and progression of erosive-abrasive defects [Johansson et al., 2002; Amaechi et al., 2003; Lussi and Jaeggi, 2008]. It is known that some people do not develop erosion of tooth hard tissues while consuming acidic food compounds, while others are prone to erosion [Wetton et al., 2007]. This may be due to differences in salivary characteristics that result in different composition of salivary pellicle [Cheaib and Lussi, 2011]. Besides intrinsic factors, extrinsic factors such as consumption of soft drinks and other erosive dietary constituents like soft and hard acidic candies may also lead to dental erosion. They often contain organic acids that dissolve during chewing or licking, thereby resulting in a decreased $\mathrm{pH}$ in the oral

\begin{tabular}{ll}
\hline KARGER & $\begin{array}{l}\text { ( ) 2013 S. Karger AG, Basel } \\
0008-6568 / 13 / 0476-0553 \$ 38.00 / 0 \quad \text { Karger }\end{array}$ \\
$\begin{array}{l}\text { E-Mail karger@karger.com } \\
\text { www.karger.com/cre }\end{array}$ & $\begin{array}{l}\text { This is an Open Access article licensed under the terms of the } \\
\text { Creative Commons Attribution-NonCommercial 3.0 Un- } \\
\text { ported license (CC BY-NC) (www.karger.com/OA-license), } \\
\text { applicable to the online version of the article only. Distribu- } \\
\text { tion permitted for non-commercial purposes only. }\end{array}$
\end{tabular}

Prof. Dr. Elmar Hellwig

Department of Operative Dentistry and Periodontology

Dental School and Hospital, Albert-Ludwigs University Freiburg

Hugstetter Strasse 55, DE-79106 Freiburg (Germany)

E-Mail Elmar.Hellwig@uniklinik-freiburg.de 
cavity [Lussi et al., 1997; Jensdottir et al., 2005, 2007; Brand et al., 2009; Wagoner et al., 2009]. Davies et al. [2008] have shown that some sour sweets were even more erosive than orange juice. The hypothesis of the present study was therefore that saliva gathered from patients with heavy erosive defects exhibits lower protective efficacy compared to saliva from patients without tooth hard tissue erosion. Sour drops were used as an erosive challenge in order to evaluate their erosive potential compared to pure citric acid.

\section{Material and Methods}

A total of 645 cylindrical enamel specimens, $3.5 \mathrm{~mm}$ in diameter, were prepared from freshly extracted bovine incisors without microscopically visible defects using a trephine bur (Brasseler, Lemgo, Germany). The specimens were placed in molds (Multiform 25-mm diameter; Struers, Copenhagen, Denmark) with the dentin surface downwards and embedded in chemically setting resin (Technovit 4071, Heraeus, Wehrheim, Germany). The embedded specimens were removed from the molds and ground plane-parallel. Then the surface of the specimens was polished to a grain of 4,000 . After the final polishing all specimens were rinsed for 5 min under running tap water. All specimens were subjected to microhardness testing (Leitz Miniload, Wetzlar, Germany) prior to experiments. Five impressions per specimen were performed (F: $1 \mathrm{~N}, 30 \mathrm{~s}$ ) and a mean microhardness value per specimen was calculated. Then the specimens were distributed among seven experimental groups in a way that the average initial microhardness per group $\left(t_{0}\right)$ was almost the same (315-320 KNH).

From 10 patients without clinical signs of dental erosion (group A) and 10 patients (group B) exhibiting severe dental erosive defects (Eccles score 2 or 3 ) each 1.2 liter of saliva was gathered in ice-chilled vials and distributed among $50-\mathrm{ml}$ aliquots in respective tubes. Subsequently the saliva was frozen at $-80^{\circ} \mathrm{C}$ and thawed before being used. Salivary flow was stimulated by chewing of a piece of chewing gum (Wrigleys Extra Professional, Chicago, Ill., USA) on 3 consecutive days at 9 and 11 a.m. The patients were not allowed to smoke, eat, drink or brush their teeth with fluoridated dentifrice at least $3 \mathrm{~h}$ before the collection of saliva. Immediately after saliva collection buffering capacity was evaluated using a simple buffer capacity testing strip (CRT buffer test, Ivoclar Vivadent, Schaan, Liechtenstein) and salivary flow rate was determined. No data concerning the reasons for erosion were collected. The use of human tissues and fluids for experimental purposes outside the body was approved by a general vote of the ethics committee of the medical faculty. Aliquots of $50 \mathrm{ml}$ of saliva from each patient were used for the preparation of the mixtures $\mathrm{AI}_{1-10}$, $\mathrm{AII}_{1-10}, \mathrm{BI}_{1-10}, \mathrm{BII}_{1-10}$, and 1 aliquot of $100 \mathrm{ml}$ was used for remineralization periods as well as for the last remineralization period. A total amount of $10 \mathrm{ml}$ each was used for the preparation of pooled saliva (control group 1).

In subgroup AI, $25 \mathrm{~g}$ of sour drops (Haribo, Bonn, Germany) was mixed with $50 \mathrm{ml}$ of stimulated saliva from each of 10 patients without clinical signs of dental erosion. In subgroup AII the same amount of saliva was mixed with $0.25 \mathrm{ml} 0.1 \mathrm{M}$ citric acid. In each subgroup 15 enamel specimens were treated with the respective mixture (patient). In subgroup BI, the sour sweets were mixed with $50 \mathrm{ml}$ of stimulated saliva gathered from patients with severe erosion. In group BII, the mixture contained $25 \mathrm{ml} 0.1 \mathrm{M}$ citric acid and $50 \mathrm{ml}$ of saliva also for each of 15 enamel specimens per patient. Three controls were prepared: group C1 $(n=15)$ contained pooled saliva from all patients $(5 \mathrm{ml}$ each). In control group C2 $(\mathrm{n}=15), 25 \mathrm{~g}$ of sour drops was mixed with $50 \mathrm{ml}$ of deionized water. In control group C3 $(\mathrm{n}=15), 0.1 \mathrm{M}$ citric acid $(25 \mathrm{ml})$ was mixed with $50 \mathrm{ml}$ of deionized water.

For the preparation of mixtures, the sour drops were cut with a pair of scissors and the respective amount was subsequently mixed with saliva using a stir bar until a uniform slurry was obtained. The sour drops consisted of glucose, starch, gelatine, citric acid, fumaric acid, gelatine, aromas, caramel syrup, Cochenille red A, chinoline yellow, and indigotine I. The manufacturer did not supply the exact percent composition. The $\mathrm{pH}$ of the different mixtures was determined with a $\mathrm{pH}$ meter (Thermo Electron Corp., Beverly, Mass., USA) at room temperature.

All enamel specimens of groups AI, AII, BI, and BII were suspended in the respective mixture for $5 \mathrm{~min}$ at room temperature, removed and rinsed with distilled water. Subsequently, they were transferred into $100 \mathrm{ml}$ of saliva and incubated for $2 \mathrm{~min}$. Then the surfaces were rinsed again with deionized water and five microhardness indentations per specimen were performed in an untouched area of the enamel surface $\left(t_{1}\right)$. Two additional demineralization/remineralization cycles followed and again microhardness was analyzed as described above after each cycle $\left(t_{2} / t_{3}\right)$. After an additional storing period in $100 \mathrm{ml}$ of saliva for $8 \mathrm{~h}$ (remineralization period) the final microhardness $\left(t_{4}\right)$ value was evaluated. The specimens of control group 1 were stored only in saliva during the whole experiment. The enamel blocks of control groups 2 and 3 were stored only in saliva after the respective demineralization periods.

\section{Statistics}

Descriptive statistics (means and standard deviations) are presented for the changes in microhardness during the different demineralization/remineralization cycles. Mean microhardness numbers at the end of the experiments were statistically evaluated using analysis of variance and Tukey's test.

\section{Results}

In table 1 , the average $\mathrm{pH}$ values of the different experimental storage mixtures are shown. There was hardly any difference in $\mathrm{pH}$ values between the mixtures prepared with saliva of patients with erosion and those without erosion. Pooled saliva exhibited a $\mathrm{pH}$ of 7.6. Salivary flow rate was high ( $>1 \mathrm{ml} / \mathrm{min}$ ) for all patients and did not differ among the two groups. Buffering capacity of saliva was determined on 3 consecutive days upon collection and was high $(\mathrm{n}=4)$ or medium $(\mathrm{n}=6)$ for patients with erosion and also high $(n=6)$ or medium $(n=4)$ for patients without erosion. These ratings were reproducible. 
Table 1. Average $\mathrm{pH}$ values of the experimental mixtures and solutions (mean \pm standard deviation)

\begin{tabular}{lll}
\hline Trial solution & Group & pH value \\
\hline Fruit drops + saliva $(\mathrm{n}=10)$ & group 1: without erosion & $3.04 \pm 0.1$ \\
Fruit drops + saliva $(\mathrm{n}=10)$ & group 2: with erosion & $3.00 \pm 0.08$ \\
0.1 M citric acid + saliva $(\mathrm{n}=10)$ & group 1: without erosion & $3.00 \pm 0.09$ \\
0.1 M citric acid + saliva $(\mathrm{n}=10)$ & group 2: with erosion & $2.92 \pm 0.08$ \\
Pooled saliva $(\mathrm{n}=1)$ & control 1 & 7.65 \\
Fruit drops + water $(\mathrm{n}=1)$ & control 2 & 2.52 \\
0.1 M citric acid + water $(\mathrm{n}=1)$ & control 3 & 2.35 \\
\hline
\end{tabular}

Table 2. Average KNH numbers ( \pm standard deviation) of enamel specimens after storage in a mixture of sour drops or citric acid with saliva originating from patients with or without erosion, respectively

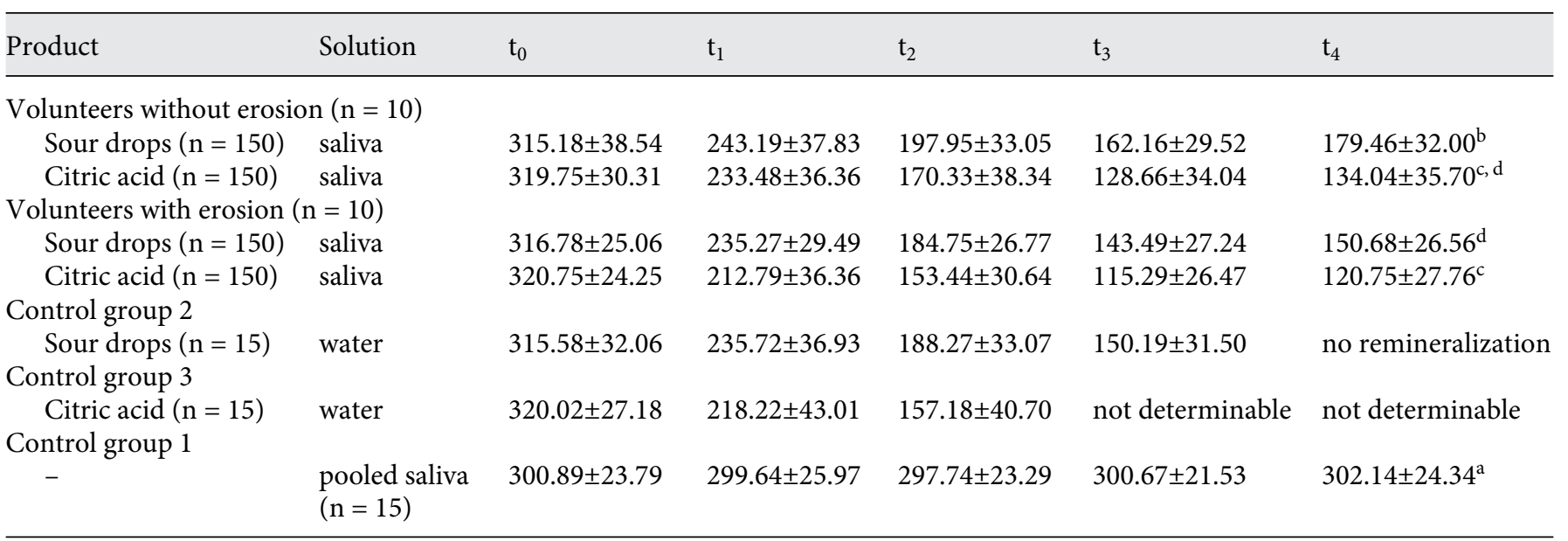

$\mathrm{t}_{0}=$ Start; $\mathrm{t}_{1}-\mathrm{t}_{3}=$ after each demineralization and remineralization; $\mathrm{t}_{4}=$ after last remineralization. Control group 2: Sour drops were dissolved in water and were not exposed to saliva after $t_{3}$. Control group 3: Citric acid was mixed with water, microhardness could not be evaluated after $t_{2}$. Different letters indicate significant differences among the groups.

Table 2 presents average microhardness values for the different experimental groups. Microhardness decreased in all experimental groups except for specimens that were treated with saliva only. At $t_{4}$, microhardness values were significantly higher $(p<0.05)$ for the mixture of sour drops with saliva of patients without erosion compared to those with erosion. The mixture of citric acid with saliva from both groups of patients did not lead to significantly different microhardness values at the end of the experiments. However, both mixtures of sour drops with saliva differed significantly from those with citric acid and saliva. In control group 3 (citric acid/water) microhardness could no longer be determined after the third erosive challenge.

In figure 1, the relative $\mathrm{KNH}$ numbers [microhardness (start) - microhardness (treated)/microhardness (start) $\times$
100] are presented except for control group 1 (only saliva), where almost no change in microhardness took place. The greatest loss of microhardness was found for the mixture of citric acid with water. The mixture of saliva from patients without erosion with the sour drops resulted in a loss of microhardness of approximately $48 \%$ at $t_{3}$ while the mixture of saliva from patients with erosion with the same product led to a loss of hardness of approximately $55 \%$. For the mixture of citric acid with saliva from patients without erosion, microhardness decreased by $60 \%$ and for patients with erosion microhardness decreased by $65 \%$, respectively. Control group 2 (sour drops plus water) showed a microhardness loss of approximately $68 \%$. After storing in saliva for $8 \mathrm{~h}\left(\mathrm{t}_{4}\right)$, the specimens of each group showed an increase in microhardness (rela- 


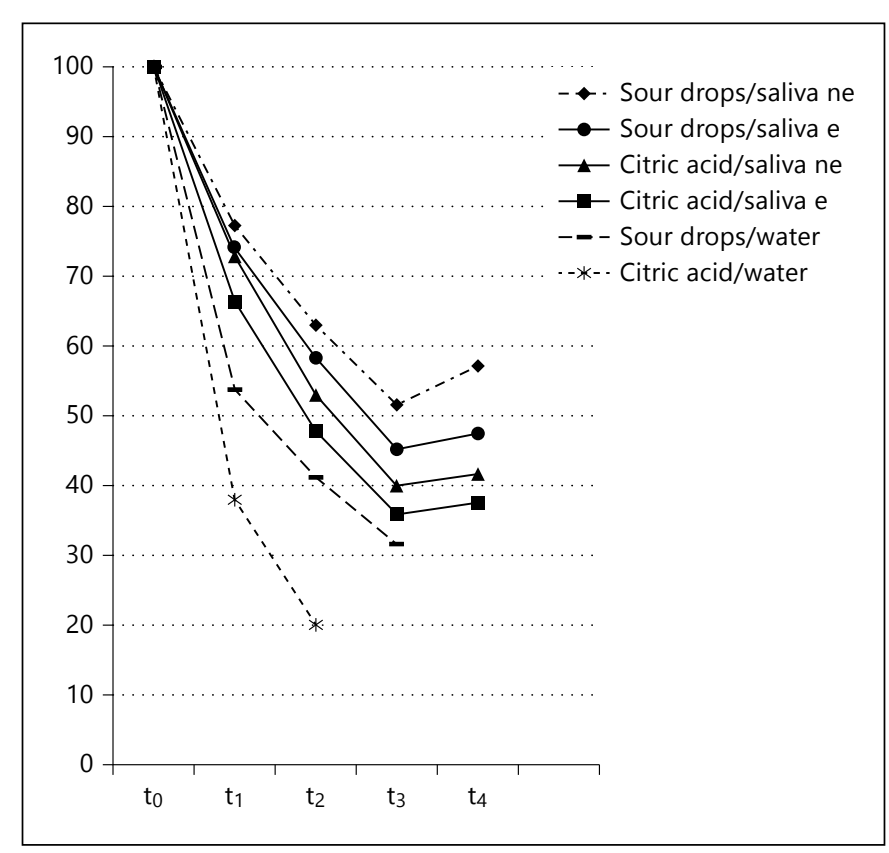

Fig. 1. Average microhardness related to initial hardness (set to $100 \%)$ after the respective experimental periods ( $\mathrm{e}=$ saliva of patients with erosion; ne = saliva of patients without erosion).

tive to the values at $t_{3}$ ) in the following order: no erosion/ sour drops, erosion/sour drops, erosion/citric acid, no erosion/citric acid, the salivary remineralizing capacity of patients without erosion tending to be better when the erosive challenge was moderate (sour drops/saliva).

\section{Discussion}

In the present study the administration of a mixture of sour drops with saliva of patients without erosion resulted in a significantly lower loss of microhardness compared to a mixture with saliva from patients with erosion, although we did not find a difference in the stimulated salivary flow rate and buffering capacity between the two groups. These findings are in accordance with reports from several other studies [Järvinen et al., 1991; Johansson, 2002; Wang et al., 2011]. It may be suspected that the saliva of patients without erosion contains certain intrinsic protective factors beyond the buffer capacity or flow rate. It is well known that the pathogenesis of dental erosion varies considerably among different persons despite consuming acidic soft drinks under similar conditions. One reason for this variation might be differences in salivary composition concerning mineral content and/or or- ganic composition of saliva leading to different protective mechanisms or different repair capacity. Piangprach et al. [2009] collected saliva from patients having erosion or not and found that protective functions with respect to erosion depend partly on salivary factors and may differ according to a person's age and the severity and site of erosion. Also Hall et al. [1999] stated that erosion appears to show considerable individual and site-specific variation. Wagoner et al. [2009] reported that sour candies dissolved in artificial saliva had less erosive capacity than those dissolved in water. Hannig et al. [2009] stated that the salivary pellicle may be regarded as an antierosive barrier and buffer and Wetton et al. [2006] also concluded from an in vitro study that a pellicle produced from human saliva offers some erosion protection when it is allowed to adhere undisturbed for at least $1 \mathrm{~h}$. In the present experiment, the enamel specimens were stored for more than $1 \mathrm{~h}$ between erosive challenges, thereby allowing the production of undisturbed pellicle. It is conceivable that the pellicle produced from the saliva of patients with erosion differs in terms of composition and/or ultrastructure compared with the pellicle from patients without erosion. In an in situ study Hannig et al. [2009] suggested that particular organic compounds originating from saliva fill erosive lacunae thereby facilitating a repair process. Kirkham et al. [2007] demonstrated that artificial self-assembling proteins facilitate remineralization processes. Kielbassa et al. [2005] could show that single proteins protect enamel against demineralization. Cheaib and Lussi [2011] pointed out that modification of salivary pellicle with casein and mucins significantly improved erosion-inhibiting properties of the human pellicle. They concluded that protein-protein interactions like cross-linking phenomena may play an important role in the effectiveness of the pellicle to prevent erosion. Hannig and Joiner [2006] claimed that the protein composition of the pellicle significantly affects the regulation of calcium phosphate crystallization. It is therefore possible that the proteinaceous framework of the salivary pellicle differed between the two experimental groups in the present study. Dawes [2008] reported that researchers identified more than 300 proteins in whole saliva. He also indicated that differences in salivary protein content exist among people because many of the protein families exhibit genetic polymorphisms.

In the present study the saliva of patients without erosion tended to result in a better remineralizing capacity compared with the saliva of patients without erosion after a moderate erosive challenge. This indicates that in addition to the possible protective effect also a remineral- 
izing function of saliva might be responsible for the findings of the present study. Amaechi and Higham [2001] also demonstrated in vitro that clarified natural saliva collected from 1 individual, but also artificial saliva, can remineralize erosively softened enamel to a certain extent. It might be speculated that some remineralization might also occur clinically, when the time between erosive challenge and putative abrasion due to toothbrushing is long enough. It may, however, take months until clinically significant remineralization occurs [Garberoglio and Cozzani, 1979]. Further, it has been shown that in persons with dental erosion $\mathrm{pH}$ recovery on the tooth surface is slower compared to a healthy control after an acidic intake [Lussi et al., 2012]. Electrolyte composition has been shown to vary considerably among different people in a study by Dawes and Dong [1995]. The authors hypothesized that calcium-complexing proteins like statherin of proline-rich proteins reduce remineralization. However, they used pooled saliva from different patients with no data about possible erosion in the respective patient's mouth. They also speculated that some intrinsic factors may vary among individuals with respect to the pathogenesis of dental erosion.

However, the results of pure lactic acid mixed with saliva or water suggest that severe acidic attacks may overwhelm this protective function. This is in agreement with the findings of Creanor et al. [2011], who reported that the defensive role of saliva decreases with prolonged exposure to acid.

The present study suggests that the results of simple in vitro studies concerning the enamel softening effects of extrinsic erosive agents cannot be translated into clinical recommendations. They allow for the testing of single or multiple factors responsible for erosion of human enam- el. However, according to Hara et al. [2008], they should be able to mimic the principles of physiological ecology. Hall et al. [1999] stressed that even the use of whole human saliva in an in vitro model does not represent the events likely to occur within the oral cavity. Besides known parameters such as the amount of titratable acid, acid clearance rate, $\mathrm{pH}$ of the product and buffer capacity of saliva, still unknown factors seem to be responsible for the formation of clinically visible erosion, e.g. the structure and composition of enamel [Attin et al., 1997], which also plays a crucial role in erosive softening of enamel.

The results of the present study indicate that intrinsic salivary components play a crucial role in the development of dental erosion. However, we were not able to offer a universally valid explanation for the different susceptibility of individuals. The main conclusion from this study is therefore that we need to be cautious when extrapolating in vitro data to clinical recommendations, because we do not yet know enough of what happens in the oral cavity of different patients.

\section{Acknowledgments}

The authors thank Petra Hess for her excellent assistance. We also acknowledge the valuable help of M. Wolkewitz (Institute of Medical Biometry and Medical Informatics, Albert-Ludwigs University, Freiburg), who analyzed the data statistically.

Contribution of authors: all authors planned the study, designed the experiments, and wrote the manuscript. F. Götz performed the experiments.

\section{Disclosure Statement}

The authors declare that there are no conflicts of interest.

\section{References}

Amaechi BT, Higham SM: In vitro remineralisation of eroded enamel lesions by saliva. J Dent 2001;29:371-376.

Amaechi BT, Higham SM, Edgar WM: Influence of abrasion in clinical manifestation of human dental erosion. J Oral Rehabil 2003;30: 407-413.

Attin T, Koidl U, Buchalla W, Schaller HG, Kielbassa AM, Hellwig E: Correlation of microhardness and wear in differently eroded bovine dental enamel. Arch Oral Biol 1997;42: 243-250.

Brand HS, Gambon DL, Paap A, Bulthuis MS Veerman EC, Amerongen AV: The erosive potential of lollipops. Int Dent J 2009;59:358362 .
Cheaib Z, Lussi A: Impact of acquired enamel pellicle modification on initial dental erosion. Caries Res 2011;45:107-112.

Creanor S, Creanor S, Alharthy N: A comparison of in vitro erosion-like mineral loss between continuous and intermittent acidic exposure with and without human saliva. Arch Oral Biol 2011;56:703-708.

Davies R, Hunter L, Loyn T, Rees J: Sour sweets: a new type of erosive challenge? Br Dent J 2008; 204:E3, discussion 84-85.

Dawes C: Salivary flow patterns and the health of hard and soft oral tissues. J Am Dent Assoc 2008;139(suppl):18S-24S.
Dawes C, Dong C: The flow rate and electrolyte composition of whole saliva elicited by the use of sucrose-containing and sugar-free chewing-gums. Arch Oral Biol 1995;40:699-705.

Garberoglio R, Cozzani G: In vivo effect of oral environment on etched enamel: a scanning electron microscopic study. J Dent Res 1979;58: 1859-1865.

Hall AF, Buchanan CA, Millett DT, Creanor SL, Strang R, Foye RH: The effect of saliva on enamel and dentine erosion. J Dent 1999;27: 333-339.

Hannig C, Berndt D, Hoth-Hannig W, Hannig M: The effect of acidic beverages on the ultrastructure of the acquired pellicle - an in situ study. Arch Oral Biol 2009;54:518-526. 
Hannig M, Joiner A: The structure, function and properties of the acquired pellicle. Monogr Oral Sci 2006;19:29-64.

Hara AT, González-Cabezas C, Creeth J, Zero DT: The effect of human saliva substitutes in an erosion-abrasion cycling model. Eur J Oral Sci 2008; 116:552-556.

Järvinen VK, Rytömaa II, Heinonen OP: Risk factors in dental erosion. J Dent Res 1991;70: 942-947.

Jensdottir T, Nauntofte B, Buchwald C, Bardow A: Effects of sucking acidic candy on wholemouth saliva composition. Caries Res 2005;39: 468-474.

Jensdottir T, Nauntofte B, Buchwald C, Bardow A: Effects of calcium on the erosive potential of acidic candies in saliva. Caries Res 2007;41: 68-73.

Johansson AK, Lingström P, Birkhed D: Comparison of factors potentially related to the occurrence of dental erosion in high- and low-erosion groups. Eur J Oral Sci 2002;110:204-211.
Kielbassa AM, Oeschger U, Schulte-Monting J, Meyer-Lueckel H: Microradiographic study on the effects of salivary proteins on in vitro demineralization of bovine enamel. J Oral Rehabil 2005;32:90-96.

Kirkham J, Firth A, Vernals D, Boden N, Robinson C, Shore RC, Brookes SJ, Aggeli A: Self-assembling peptide scaffolds promote enamel remineralization. J Dent Res 2007;86:426-430.

Lussi A, Jaeggi T: Erosion - diagnosis and risk factors. Clin Oral Investig 2008;12(suppl 1):S5S13.

Lussi A, Portmann P, Burhop B: Erosion on abraded dental hard tissues by acid lozenges: an in situ study. Clin Oral Investig 1997;1: 191-194.

Lussi A, von Salis-Marincek M, Ganss C, Hellwig E, Cheaib Z, Jaeggi T: Clinical study monitoring the $\mathrm{pH}$ on tooth surfaces in patients with and without erosion. Caries Res 2012;46:507512.
Piangprach T, Hengtrakool C, Kukiattrakoon B, Kedjarune-Leggat $\mathrm{U}$ : The effect of salivary factors on dental erosion in various age groups and tooth surfaces. J Am Dent Assoc 2009;140: 1137-1143.

Wagoner SN, Marshall TA, Qian F, Wefel JS: In vitro enamel erosion associated with commercially available original-flavor and sour versions of candies. J Am Dent Assoc 2009;140:906-913.

Wang P, Zhou Y, Zhu YH, Lin HC: Unstimulated and stimulated salivary characteristics of 12-13-year-old schoolchildren with and without dental erosion. Arch Oral Biol 2011;56: 1328-1332.

Wetton S, Hughes J, Newcombe RG, Addy M: The effect of saliva derived from different individuals on the erosion of enamel and dentine: a study in vitro. Caries Res 2007;41:423-426.

Wetton S, Hughes J, West N, Addy M: Exposure time of enamel and dentine to saliva for protection against erosion: a study in vitro. Caries Res 2006;40:213-217. 